\title{
Divided Classroom: A New Exploration of College Classroom Teaching Reform
}

\author{
Hao Jin \\ Nanchang Normal University, Nanchang, Jiangxi,330032, China \\ ABSTRACT. "Divided Classroom" is a new teaching mode recently proposed. It \\ allocates teaching time reasonably and can realize the effective combination of \\ teacher teaching and student discussion. In view of the current status of university \\ curriculum professors, this paper takes several typical university courses as an \\ example to explore the feasibility of applying the "divisional classroom" teaching \\ model. Practice has proved that the use of the "divisional classroom" teaching \\ model has significant effects in mobilizing students' enthusiasm for learning, \\ reducing teachers' teaching burden, improving teaching effectiveness and improving \\ teaching quality.
}

KEYWORDS. College Classroom Teaching; Divided Classroom ; Teaching Method

\section{Introduction}

"Divided Classroom” is a new teaching mode proposed by Professor Zhang Xuexin of Fudan University in October 2013. The basic idea is to divide the class time into two according to the actual situation, half of the time is assigned to the teacher for teaching, and the other half is allocated. Students will be exchanged and studied in the form of discussion, and pay attention to the first-school teaching, the teacher will teach first, and the students will learn later. The "divisional classroom" divides the teaching activities into three parts, namely, the teacher's lecture presentation, the student's after-school internalization (Assimilation) and the student's classroom discussion (Discussion), also referred to as the PAD classroom. The key point is that the lectures and interactive learning are separated in time according to the actual course, so that students have sufficient time to personalize the internalization between classroom teaching and class discussion. In order to achieve a good interaction between teachers and students, students and students, not only the students' independent thinking ability, but also the students' interest in independent learning. "Divided classroom" can effectively reduce the heavy teaching burden of teachers, transform the dominant position of teachers into counseling status, and gradually hand over the initiative of the classroom to students. On the one hand, "divisional classrooms" can fully absorb the advantages of traditional classrooms, and through the teaching of teachers, students can quickly 
acquire the best knowledge, such as basic framework and difficult knowledge. On the other hand, "divisional classroom" can overcome the phenomenon of passive acceptance of students in traditional teaching-oriented teaching. Guide the students to actively participate in classroom teaching activities with the help of teachers. Independent thinking under the class, completing homework independently, actively discussing problems in class. To increase the communication between teachers and students in teaching and the communication before the students, teachers and students work together to improve the quality of teaching.

\section{Points to The Classroom Concept}

This new teaching method has been recognized by teachers and students in the short term, mainly due to its teaching philosophy in line with China's national conditions. First of all, "chamber discussion" is a key innovation in the classroom. Half of the class time is assigned to the teacher and half is given to the students for discussion. The content of the student discussion is the content taught by the previous class teacher. The educator Dewey believes that "thinking as the center of learning" is an important condition for effective learning. The so-called thinking is to identify the relationship between what we try and the results that result from such an attempt. The process that students prepare for discussion is also the process of thinking. Students come to class to be prepared, avoiding formal discussions, significantly improving the quality of the discussion, activating the classroom atmosphere, and enhancing students' enthusiasm and initiative.

Second, flexible classroom arrangements. The class is not mandatory for the proportion of lectures and discussions. It can be opened in five or five, eight in two, or even nine. For example, when you first start class, ask students to discuss several issues related to the previous lesson. Again, "divide" with "combination". The subclassroom emphasizes giving students sufficient time to "internalize”. Mazur divides learning into two steps: "knowledge transfer” and “absorption internalization”. It is a process of internalizing knowledge that allows students to self-learn textbooks under the class. The students' self-learning content is clear, the goals are clear, the learning results will be feedback in the next section of the discussion class, and the students' self-study results will be part of the process evaluation, so that independent learning and classroom learning can be effectively unified. The split class actually consists of three links: the first class is taught by the teacher based on the main frame of the textbook, the key points and difficulties; the students learn the content related to the chapter independently between the two classes, and ask the corresponding questions; The students in the second class will discuss the relevant issues in groups, and the teachers will provide timely counseling and summary. So the split class is also called the PAD class, which is Presentation - Assimilation - Discussion. 


\section{Rationality of The Class}

In the traditional classroom, the teacher's teaching is intended to be complete and detailed, and the students have no room to play and tend to accept passively. In the dichotomy class, the teacher has guidance, but does not exhaust the content, leaving the students to further explore the space, which can lead students to take the initiative to learn. Through the classroom teaching, the students get the basic framework, understand the key points and difficulties, and greatly reduce the difficulty of learning after class. Students must take homework to participate in discussions, and they will be more conscientious and active when they are under the pressure of their peers. Homework scoring, excellent homework is demonstrated, and students are encouraged to externalize their learning outcomes into high-quality homework. The learning objectives are clear under the class, but when to learn, how to learn, how to learn, students arrange themselves, and have strong autonomy.

In the traditional classroom, the teacher is responsible for the organization, presentation, interpretation, and summary of all content, and the preparation for the lesson is large. In the dichotomy class, the teacher only needs to grasp the essentials, leaving other content to the students to learn, and the amount of lesson preparation is significantly reduced. Short teaching time reduces the need for students' attention and reduces the "performance" teaching that is purely eye-catching. During the group discussion, the teachers patrolled between the groups but did not get involved in the discussion, and the burden was small. Job corrections require only a rough grading, simple feedback, and not much time. Display and commentary assignments are highly targeted, students are interested, and the teaching effect is good. It also reduces the preparation of teaching materials and reduces the burden of preparing lessons. In the dichotomous classroom, the mechanical components in the teaching process are reduced, the guiding components are improved, and the teacher's role is changed from covering content, instilling knowledge, and guiding students to learn. The content taught by the teachers is the part that the students feel difficult and the reading is not easy to understand. The students will have more respect and evaluation of the teachers' knowledge.

In the traditional classroom, the teachers teach each student to study and lack communication opportunities. Students learn by themselves are rather boring, and it is not easy to solve problems when they encounter problems, and they are easily frustrated. It is difficult for students to gather together under the class, and the learning environment is not easy to guarantee. The effect of group interaction learning is not good. In the classroom, the interactive communication is put into the classroom, the learning environment is good, and the students bring questions and cooperate with each other to answer. Students exercise their ability to express their opinions in discussions, learn to draw on the perspectives of others, inspire each other, promote and deepen understanding, and enhance mutual understanding among students and deepen friendship. It is difficult to participate in the discussion without class learning, and the absence of classes will also affect the entire group of discussions, which will strengthen the teamwork awareness of students. Students have the opportunity to interact with teachers and teachers can participate in 
discussions at any time. In general, the range of interactions between students and teachers has greatly improved.

In the traditional classroom, students get scores through several assessments, such as mid-term, final exams or term papers. Depending on the content of the exam and the on-the-spot play, the scores are high and the evaluation accuracy is low. The exam focuses on rote memorization, and the ability to think is not enough. On the other hand, the traditional teaching concept hopes that students will do their best in every class, the goal is too ideal, and they do not consider the learning needs of students. Students should be encouraged to plan their investment in different courses according to their own conditions, subject to the requirements of the school. For example, for a particular course, not every student wants to get good grades, some students are not interested, some students have insufficient ability, some students have insufficient time, some students feel that the level of teachers is not high, and some students think that it is meaningful for their future development. Not big. In these cases, students may only pass the pass. Learning evaluation should respect the different learning needs of students, so that low-demanders can have a guaranteed learning plan, so that high-demanders can show excellent space.

At present, many courses in colleges and universities mainly use the method of final exams to evaluate. Students do not usually study, and they are assessed according to strict standards. Many students cannot pass the exam. Teachers can only use the method of prioritization before the exam to reduce the difficulty of the exam and let most students pass. This will further lead students to not study at all times, and to die before the test, forming a vicious circle. Divided classrooms encourage regular learning, and the efforts that should be paid for effective learning are spread throughout the semester. Every week, after the teacher teaches, the students need to complete the internalization and absorb the learning results in the form of homework. Reading notes emphasize the individual characteristics of the students. In the process of completing the reading notes, students have the ability to organize, summarize and summarize the contents of the books, as well as deep understanding and divergent and creative thinking. The split class begins with the group discussion of the students. The students review the last content and naturally enter the follow-up content, so that students can enter a good learning state without importing skills. After one week of teaching, after-school review, group discussion and learning the same content three times, in line with the law of memory, can effectively slow the rate of forgetting. Throughout the semester, students' deep learning and comprehension learning have been ongoing. Before the exam, students only need to review some basic concepts that need to be recited, and they are not nervous. These changes in the learning process can make a very positive contribution to improving learning outcomes. 


\section{Successful Elements of The Classroom}

First, teach first. Cognitive psychology emphasizes the role of knowledge and believes that knowledge is the main factor determining human behavior. The second class teaches knowledge, provides students with a cognitive model and structure, and allows students to form certain cognitive pressures and cognitive confusion, which can enhance students' desire for exploration and motivation. Second, a reasonable grouping. Student discussion in the class is not limited by the number of students in the class. According to the principle of "heterogeneity within groups, homogeneity between groups", 4-6 students in each group should consider the ratio of male to female and the difference in scores. Third, select textbooks. The quality of students' internalization of knowledge depends on the quality of the input. Excellent teaching materials are an important guarantee for successful teaching. Professor Zhang Xuexin's psychology class used a Chinese translation of the original English textbook. He believes that the content of this textbook is substantial, superior to the general domestic textbooks and network resources, students can learn advanced knowledge; the supporting exercises of the textbooks are reasonable and novel, can inspire students' critical thinking, and drive students to propose information on all aspects. Question and ask questions. Excellent textbooks can also inspire teachers to allow teachers to examine professional knowledge from a higher level and from an updated perspective. This also puts higher demands on the quality of teachers.

\section{Conclusion}

Teachers and students who have practiced in the classroom have generally reflected a lot of benefits. The student's learning ability has improved, and the learner's critical thinking, speaking ability, and leadership skills have been exercised, stimulating the motivation for continuous learning. Teachers reduce some of the mental energy loss caused by anxiety, and enhance professional happiness and sense of accomplishment. The divisive classroom focuses on the reform of the teaching process and does not require a lot of investment. It is an economic and practical teaching reform. How to practice the dichotomy classroom in multiple courses and further optimize it by means of network and high-tech is the direction for teachers to explore in the future.

\section{References}

[1] Zhang Xuexin (2014). Divided Classroom: A New Exploration of College Classroom Teaching Reform . Fudan Education Forum, 12( 5) : 5-10.

[2] Li Zhen (2016). Exploring and researching the "divisional classroom" teaching mode in the teaching of "Advanced Mathematics" . Education and Teaching, ( 22) : 71.

[3] Zhang Boya (2015). Divided Classroom: A New Idea of College English Classroom Teaching Reform . Science and Wealth, 7(12) : 803.

\section{Published by Francis Academic Press, UK}


[4] Han Xiuting (2016). The application of the "divisional classroom" teaching mode in ideological and political theory courses. Journal of Jinhua Vocational and Technical College, 16( 5) : 26 - 29.

[5] Song Jianping, Wang Hongbin (2016). The application of the "divisional classroom" teaching mode in the teaching of organic chemistry course. Journal of Wenshan University, 29( 3) : 83 -85. 